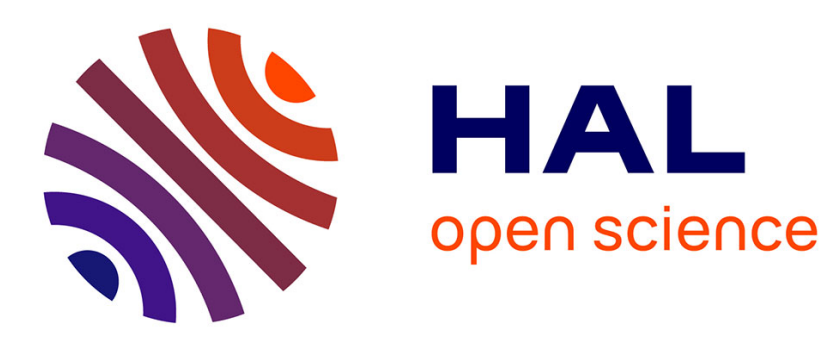

\title{
First stages of crystallization of the poly(ethylene oxide)-resorcinol molecular complex
}

\author{
C. Bourgaux, L. Paternostre, M. Dosière
}

\section{To cite this version:}

C. Bourgaux, L. Paternostre, M. Dosière. First stages of crystallization of the poly(ethylene oxide)resorcinol molecular complex. Journal de Physique IV Proceedings, 1993, 03 (C8), pp.C8-29-C8-32. 10.1051/jp4:1993806 . jpa-00252225

\section{HAL Id: jpa-00252225 https://hal.science/jpa-00252225}

Submitted on 1 Jan 1993

HAL is a multi-disciplinary open access archive for the deposit and dissemination of scientific research documents, whether they are published or not. The documents may come from teaching and research institutions in France or abroad, or from public or private research centers.
L'archive ouverte pluridisciplinaire HAL, est destinée au dépôt et à la diffusion de documents scientifiques de niveau recherche, publiés ou non, émanant des établissements d'enseignement et de recherche français ou étrangers, des laboratoires publics ou privés. 


\title{
First stages of crystallization of the poly(ethylene oxide)-resorcinol molecular complex
}

\author{
C. BOURGAUX* ${ }^{*}$ L. PATERNOSTRE and M. DOSIÈRE \\ Université de Mons-Hainaut, Département des Matériaux et Procédés, Place du Parc 20, 7000 Mons, \\ Belgium \\ * LURE, Bât. 209D, Université de Paris-Sud, 91405 Orsay cedex, France
}

\begin{abstract}
Time-resolved SAXS has been used to follow isothermal crystallization in the PEO 6000/ Resorcinol molecular complex. It has been shown that the complex exhibit crystals with PEO chains in the fully extended form. The initial stages of crystallization are strongly dependent on the temperature: at high supercooling transient once-folded chains crystals are evidenced. They thicken in a single step to give extended chain crystals.
\end{abstract}

\section{INTRODUCTION}

Poly(ethylene oxide) (PEO) is a powerful tool for studying crystal growth and chain folding in a melt-crystallised polymer. Indeed low molecular weight fractions of PEO $(2000<\mathrm{Mw}<15000)$ crystallize with chains either fully extended or folded an integral number of times $(n=1,2,3 \ldots)$. The thickness of lamellae increases discontinuously with increasing crystallization temperature $(1,2,3)$.

$\mathrm{PEO}$ is also an unusual polymer since it forms molecular complexes with various derivatives of benzene such as resorcinol $(\mathrm{C} 6 \mathrm{H} 4(\mathrm{OH}) 2)$,paranitrophenol(C6H5NO3) or paradichlorobenzene.

The occurence of a molecular complex in the $\mathrm{PEO} /$ resorcinol system has been reported by Myasnikova and al.(4),Cheng and al(5), and Dosiere and al.(6) The stoichiometry of the complex is 2:1 (i.e 2 monomeric PEO units for 1 resorcinol molecule ). The molecular complex is stabilized by formation of hydrogen bonds. Upon cooling from the melt it crystallizes as large spherulites. The unit cell contains 8 PEO units and four resorcinol molecules.Its parameters are still debated.

The aim of this note is to gain insight into the lamellar microstructure of the complex using small-angle $\mathrm{X}$-ray scattering. Investigations are focused on the first stages of crystallization.

\section{EXPERIMENTAL}

PEO of low molecular mass $(\mathrm{Mw}=6000)$ was obtained from Hoechst. Resorcinol was purchased from Merck. Samples were put in a $1 \mathrm{~mm}$ diameter capillary.

SAXS experiments were performed on beamline D24 of the LURE-DCI synchrotron radiation source. Detailed experimental set-up has been described elsewhere.

Data are plotted as intensities I,log I and Iq2 versus the scattering vector $q=4 \pi / \ln \sin (\theta / 2)$ where $\theta$ is the scattering angle and $\lambda$ the $X$-ray wavelength.

Isothermal crystallizations were carried out with a modified Mettler FP52 hot stage set in the beam. The samples were heated to $98^{\circ} \mathrm{C}$, above the melting temperature, and then cooled at $10^{\circ} \mathrm{C} / \mathrm{mn}$ down to the chosen temperature. The scattering curves were recorded in situ each $200 \mathrm{~s}$.

\section{RESULTS AND DISCUSSION.}

The $\mathrm{PEO} /$ resorcinol complex was crystallized at temperatures ranging from $30^{\circ} \mathrm{C}$ to $75^{\circ} \mathrm{C}$. The scattering patterns were then recorded at room temperature 5 or 6 narrow,equidistant,peaks can be seen whose position yields the average distance between crystalline lamellae (long period): $\mathrm{L}=370 \mathrm{~A}$. This value corresponds to chains in the extended form. $\mathrm{L}$ is insensitive to crystallization temperature. 


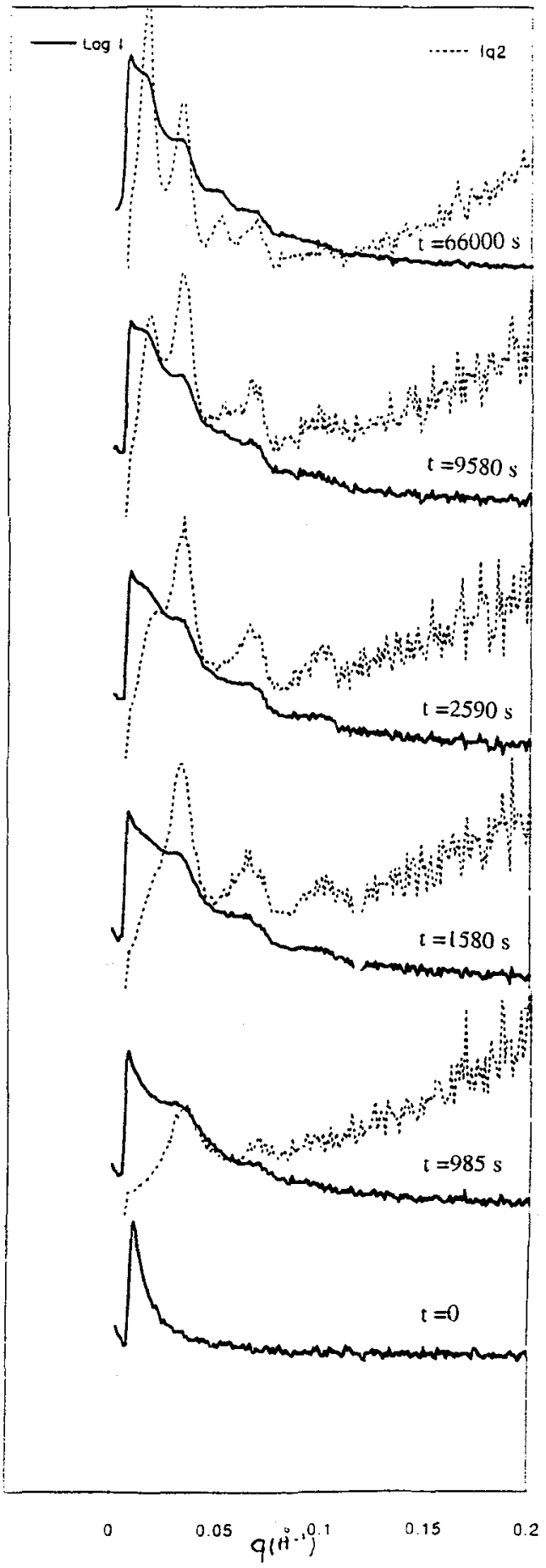

Fig 1a: Evolution of SAXS scattering curves during crystallization of the complex at $\mathrm{T}=45^{\circ} \mathrm{C}$

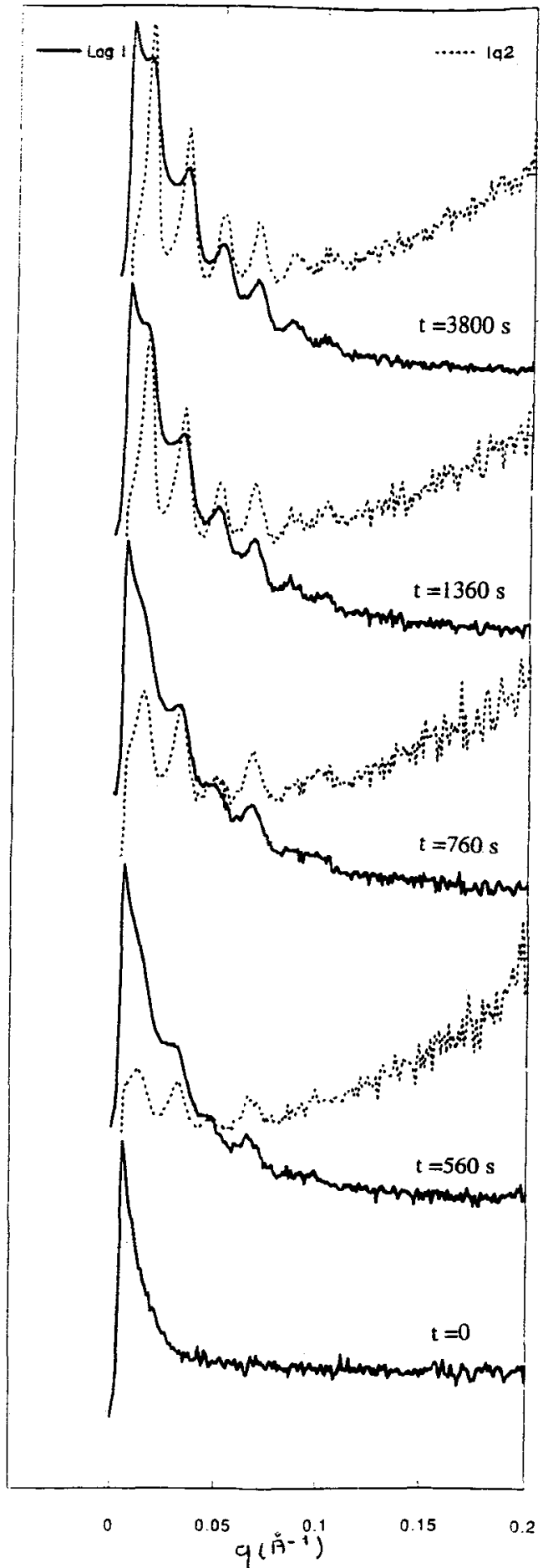

Fig 1b: Evolution of SAXS scattering curves during crystallization of the complex at $\mathrm{T}=60^{\circ} \mathrm{C}$ 
The unusual number of orders observed relies upon the regularity of the thickness and stacking of lamellae and upon the high crystallinity of the complex.

How the complex crystallizes during extended chain crystal formation is an unanswered question. Time -resolved SAXS can shed light on possible transient states.

The complex exhibits two different behaviours, depending on the supercooling.

Fig( 1a) shows a selection of scattering curves recorded at different times during isothermal crystallization at $\mathrm{Tc}=45^{\circ} \mathrm{C}$. During the initial stages of crystallization a rather broad peak and its second order (best seen in the Iq2 versus q representation)appear.The corresponding long period is close to that of once folded chains crystals. This SAXS peak is seen to narrow gradually ,indicating perfection processes. Then the growth of once-folded chains crystals gives way to that of extended chains crystals: a new scattering peak, representative of extended chains crystals, is observed. Its position remains constant (Fig2a). Fig(3a) shows how the heights of the peaks (which are a crude measure of the intensities) change during the experiment.(Note that the second peak corresponds to once-folded chains crystals and to the second order of the first peak.) It has to be pointed out that growth of extended chains crystals little contributes to the overall scattered intensity. The onset of this crystallization takes place when the overall scattered intensity has reached a plateau. This suggests that extended chains crystals results to a great extent from stepwise thickening of folded chains crystals.

By contrast , at low supercooling, curves give evidence that extended chains crystals are formed as soon as the complex crystallizes. An example is given in Fig.(1b).At $\mathrm{Tc}=60^{\circ} \mathrm{C}$ extended chains crystals and once-folded chains crystals grow simultaneously on a short time scale. Rapidly, growth of extended -chains crystals prevails. The evolution of the heights of the peaks is reported in Fig $(3 b)$ Note that the position of the peaks remains constant during all the crystallization. (Fig $2 b$ )

From the above results it follows that folded chains crystals are less stable than extended chains crystals: as crystallization time increases, they always tend to thicken in a single step to reach full chain extension. This refolding is slower at low temperatures. However at high supercooling,the growth rate of once-folded chains crystals exceeds that of extended chains crystals. So, during the initial stages, crystallization of once-folded chains takes over.

It should be noted that the long period,measured at the crystallization temperature, slightly increases as a function of temperature. This cannot be accounted for only by thermal expansion. This increase can probably be correlated with the molecular weight distribution of PEO and the segregation, at high temperature, of short chains. At low temperature all the chains co-crystallize.At high temperature the shortest chains remain in the liquid state: the thickness of lamellae is determined by the length of longer chains. By contrast the long period,measured at room temperature, does not depend on the crystallization temperature. This suggests that ,upon cooling to room temperature,the shortest chains crystallize in turn so that lamellae of slightly different thickness are randomly stacked.Hence the mean distance between lamellae decreases.

\section{CONCLUSION}

Complexation of PEO with resorcinol enhances the growth of extended chains crystals and deeply modifies the initial stages of crystallization: in pure PEO of molecular weight 6000 these crystals are only evidenced for crystallization temperatures close to the melting point, in coexistence with once-folded chains crystals (2). Moreover,integral folding chains crystals are formed through thickening or thinning processes following the development of non-integral folding chains crystals (7).

It has also been shown that the first stages of crystallization of the complex are critically dependent on the temperature. The influence of the PEO molecular weight will be highlighted in a forthcoming paper.

\section{REFERENCES}

1. J.P. Arlie,P. Spegt and A. Skoulios Makromol. Chem.,1966,99,160

2. P. Spegt, Makromol. Chem.,1970,140,167

3. A.J. Kovacs, A. Gonthier and C. Straupe J. Polym. Sci. ,1975,C50,283.

4. R.Myasnikova, E.F. Titova and E.S. Obolonkova Polymer, 1980,21,403

5. C. Cheng and L.A. Belfiore Polym.Prepr. ,1989,30,325

6 E.Delaite,J.J Point,P. Damman and M. Dosiere Macromol.1992,25,4768

7. S.Z.D. Cheng,A. Zhang and J. Chen J. Polym. Sci. Part C:Polym. Letters, 1990,28,233. 


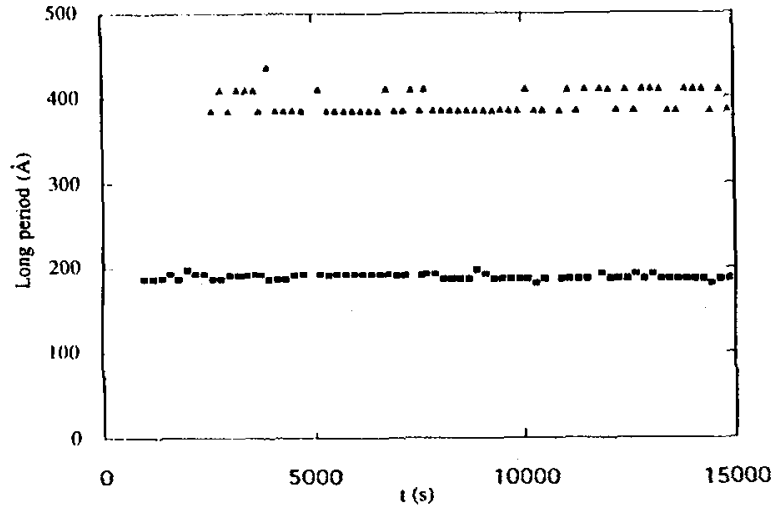

Fig 2a: Long period measured during crystallization at $T=45^{\circ} \mathrm{C}$ (Note that corresponds to the average distance between extended chains crystals and corresponds to the average distance between once-folded chains crystals or to hall the long period of extended chains crystals)

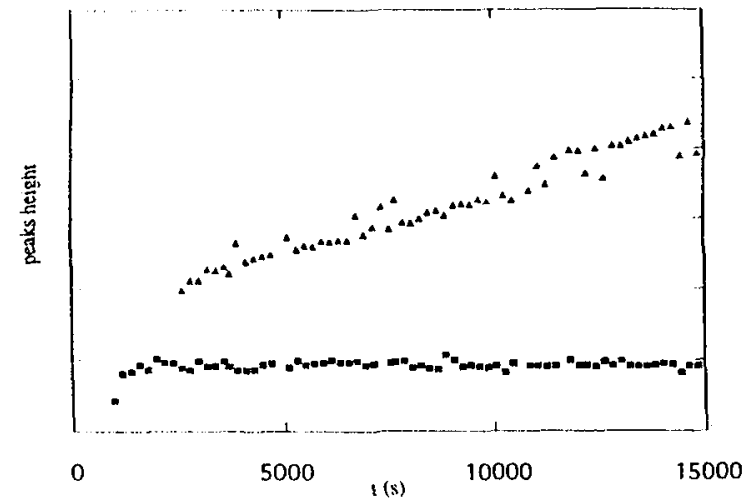

Fig $3 \mathrm{a}$ : Evolution of the heights of the first two peaks during crystailization at $\mathrm{T}=15^{\circ} \mathrm{C}$ ( $A$ corresponds to extended chains crystals; corresponds to oncefolded chains crystals and to the second order of the first peak)

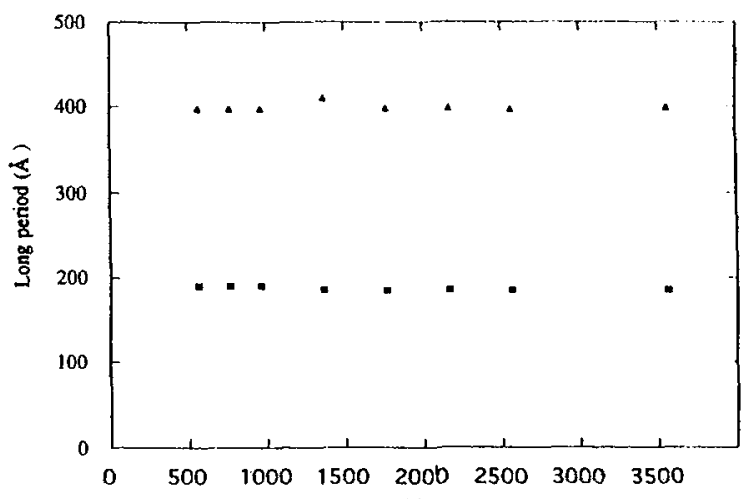

$t(s)$

Fig 2b: Long period measured during crystallization at $T=60^{\circ} \mathrm{C}$ (Note that corresponds to the average distance between extended chains crystals and corresponds to the average distance between once-folded chains crystals or to half the long period of extended chains crystals)

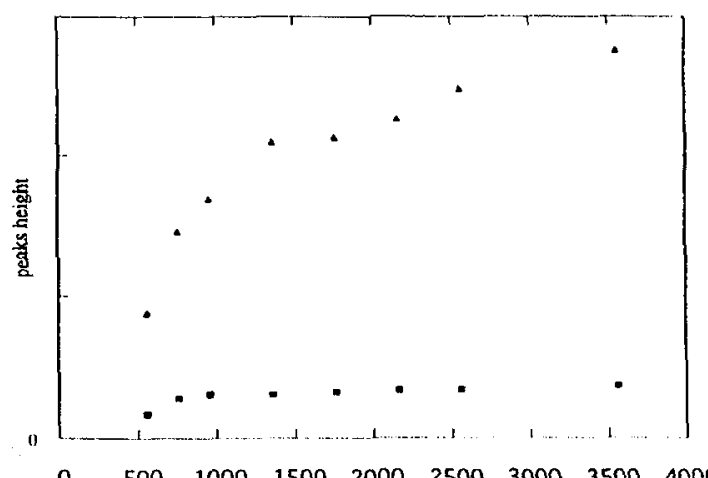

$\begin{array}{lllllllll}0 & 500 & 1000 & 1500 & 2000 & 2500 & 3000 & 3500 & 4000\end{array}$ $1(\mathrm{~s})$

Fig 3b:Evolution of the heights of the first two peaks during crystallization at $\mathrm{T}=60^{\circ} \mathrm{C}$ corresponds to extended chains crystals; folded chains crystals and to the second order of the first peak) 